\title{
Electroconvulsive Therapy: The Struggles in the Decision-Making Process and the Aftermath of Treatment
}

\author{
Marilyn Smith, PhD, PMHNP \\ West Virginia University, School of Nursing, Charleston, West Virginia, USA \\ Jason Vogler, PhD \\ University of North Carolina, School of Psychology, Butner, North Carolina, USA
}

Fahd Zarrouf, MD

Cleveland Clinic, Cleveland, Ohio, USA

\section{Crystal Sheaves, FNP-BC}

West Virginia University, School of Nursing, Charleston, West Virginia, USA

\author{
Jane Jesse, MD \\ West Virginia University, School of Behavioral Medicine \& Psychiatry, Charleston, West Virginia, USA
}

\begin{abstract}
The perceptions of patients and their family members about electroconvulsive therapy (ECT) are crucial to understanding the meaning attached to having ECT and the impact it has on quality of life. Thus, in this qualitative study, patients and their family members described their perceptions of having electroconvulsive therapy (ECT). The experience occurred in two distinct periods in the patient's life: making the decision to have ECT and the physical and emotional aftermath of treatment. One of the most important themes in the study was a need for patients and families to be better informed about the risks of ECT.
\end{abstract}

Major Depressive Disorder (MDD) is a major health problem within the United States affecting about $16 \%$ of the population. Further, according to the World Health Organization (http://www.who.int/mental_health/management/depression/definition/en/en/), by the year 2020, clinical depression is expected to become the second leading cause of disability worldwide (after heart disease). MDD is a disabling and often chronic illness. People who suffer from depression are often functionally impaired and are at risk for suicide. According to a National Institutes of Health (NIH; 2005) survey of all persons who experienced MDD, one-third considered suicide and $8.8 \%$ reported a suicide attempt.

Although antidepressants are currently the first line of treatment for depression, electroconvulsive treatment (ECT) is often

Address correspondence to Marilyn Smith, West Virginia University, School of Nursing, 507 Woodbridge Drive, Charleston, SC 25311. E-mail: msmith@hsc.wvu.edu the treatment of choice for patients whose symptoms fail to remit with the use of psychopharmacology, who have depression with severe psychosis, who are experiencing an unrelenting lethal suicidal threat, or who have a medical condition that prohibits the use of psychotropic medication (Khalid et al. 2008). Patients with schizophrenia, mania, delusions, catatonia, neuroleptic malignant syndrome, and Parkinsonism also have had positive responses to ECT (Greenberg \& Kellner, 2005; Tharyan \& Adams, 2005).

Significant improvements in ECT in recent years have made it a safe and effective treatment for severe mental disorders (Fink, 2001; Nuttall, et al., 2004; Scarano, Felthous, \& Early, 2000). Indeed, ECT is generally regarded as the safest procedure performed under general anesthesia, with a reported mortality rate of $0.002 \%$ (Greenberg \& Kellner, 2005; Nuttall et al., 2004). Despite its proven safety and effectiveness, it remains one of the most controversial and poorly understood psychiatric treatments. Considerable stigma continues to surround ECT. Some view ECT as a painful, barbaric, dangerous, and inhuman treatment that includes pain, being "shocked," and having one's memory permanently wiped out (Dowman, Patel, \& Rajput, 2005). A survey of the general population by Lauber et al. (2005) found that $57 \%$ of respondents considered ECT a harmful treatment and only $1.2 \%$ were in favor of ECT. Studies of patients' who have had ECT have revealed both positive and negative experiences, including fear of the procedure, memory loss, and an increased sense of self (Koopowitz et al., 2003; Reid, 1999; Rose et al., 2003).

The cognitive side effects of ECT, which include shortterm and long-term cognitive impairment, can be the most 
troublesome for patients. Generally these effects are mild and acceptable, but for a small number they may be more extensive. The patient may experience an anterograde amnesia (impairment in retaining new memories after ECT), and/or retrograde amnesia (forgetting memories from the time period before ECT). Anterograde amnesia usually is resolved within one to three weeks. Retrograde amnesia is considered the most serious adverse cognitive effect of ECT. Loss of memories of some events occurring before ECT may be permanent. The etiology for this amnesia is unknown (Greenberg \& Kellner, 2005).

Health care providers need to be aware of patients' and families' perceptions of the impact ECT has on both their shortterm and long-term quality of life and the factors that influence these perceptions. Only one study was found that examined both patients' and families' perceptions of having ECT. Rajkumar, Saravanan, and Jacob (2007) found that family members felt coerced to give consent for the treatment and patients expressed concerns regarding cognitive deficits. However, in this study interviews were conducted shortly after the patients completed their series of ECT, and this short follow-up did not allow for views of ECT's long-term effects. Thus questions remain about the extent and duration of improvement in psychiatric symptoms and the negative effects of memory loss following ECT.

\section{METHOD}

The study used the existential-phenomenological method outlined by Thomas and Pollio (2002). Existentialphenomenology is a paradigm that blends the philosophy of existentialism with the methods of phenomenology. Existentialism stresses individual existence, individual freedom, and responsibility (Lescoe, 1974). The methods of phenomenology were what Husserl and other philosophers used to conduct their systematic inquiries of those things we take for granted in everyday life (Thomas \& Pollio, 2002). Phenomenology attempts to describe the lived experience of an individual through his or her perceptions of the experience (Merleau-Ponty, 1962). According to Thomas and Pollio (2002) "the major reason for the primacy of perception in Merleau-Ponty's phenomenology is that it provides a direct experience of the events, objects, and phenomena of the world" (p.14). Although the phenomenologist expects to find diversity in human experience, he or she also expects through this diversity to extract the essential themes for the participants concerning the phenomenon of intent. Thus, the goal of phenomenology is to describe the experience of a given phenomenon as the participants experience it, not as it fits a theory or the researcher's expectations. This study sought both patients and family members' perceptions of the experience of having ECT and the impact they felt it had on their life.

Approval for the study was obtained from the Charleston Area Medical Center/West Virginia University Institutional Review Board. Participants were recruited from a hospital located in a mid-size southern U.S. city using posters and letters to patients known to have had ECT more than six months ear- lier. This information was obtained from the hospital and over 100 letters were sent. Information on how to contact the researcher was given in the letter. Those who chose to contact the researcher were given more information and, if they chose to participate in the study, verbal consent was obtained on the phone and an interview date was arranged. After informed consent was obtained from participants, they were asked to fill out a demographic questionnaire and to participate in a face-to-face audiotaped interview. The interviews began with the prompt, "Tell me about how ECT has impacted the quality of your life (or your family member's life)." Further questions were limited to areas of clarification or elaboration; all questions flowed from the dialogue.

Individual transcripts were analyzed using a hermeneutical approach. No passages were taken out of context, and the respondent's own words were used to support an interpretation. Participant transcripts were then related to each other to identify common patterns or global themes (Thomas \& Pollio, 2002). All of the transcripts were read in a group context to reduce researcher bias. Subsequently, an overall thematic description was developed of the meaning that ECT had on one's life.

\section{SAMPLE}

The study included English speaking adults who met the following criteria: (a) Patient or family member of a patient who had received the last ECT treatment more then six months ago; (b) not currently being treated for a psychotic illness; (c) able to discuss the experience; (d) able to read and write. A total of 16 people, 5 males and 11 females, were interviewed. Nine were patients and 7 were family members. Participant's ages ranged from 32-88 years of age. All participants were white except for a father and his daughter who were black. The education level ranged from high school graduate to having a graduate degree. All the patients, except one, were medically disabled. All patients were diagnosed with Major Depression except for one who was diagnosed with Schizophrenia. The total number of ECT patients received ranged from 5-100 treatments.

\section{RESULTS}

The experience of having ECT came in two distinct periods in the participants' life: making the decision to have ECT and the aftermath of ECT. Participants discussed in detail how they came to decide to have ECT and the feelings they experienced after having ECT.

\section{The Decision-Making Process}

Both patients and family members described how the decision to have ECT was made, with the following subthemes: (1) the anguish of having a mental illness, (2) last resort treatment, and (3) blind trust. 


\section{Anguish of Mental Illness}

Every participant spoke of the anguish of having a mental illness. Their pain and torment was clear, as in the following excerpts:

The emotional just gets to the point that you would do anything to make it stop. Suicide begins to be a rational thing. (Bill)

I was flawed, ... kind of felt like nothing ... I felt depressed. When I was really depressed, I used to say that it was only my skin that was holding me together. If there was a break in my skin you know I would just fall out. That was the only reason I had a shape because there was nothing in there. (Carol)

Barb reminds us how difficult it is to keep a job when a person suffers from depression:

I missed a lot of work ... unfortunately, I lost one job because I missed too much work and then, the next job I got, they were lenient about letting me have time off, so that helped, but I didn't feel like I could commit to doing anything because I never knew how I was going to feel. So, I didn't take much leadership in activities. I would of liked to have been more active in them, but I didn't know if I would be suicidal that week or just feeling depressed or whether I felt good enough to do it.

Sandy relates what it was like to care for her husband who was depressed:

When he became depressed I became a care giver. He looked to me to make every decision and, I mean, even though he continued to hold his job, I believe his job was probably in jeopardy by that time ... We had got ourselves into this situation where without his insurance, which was through his employer, we couldn't of afforded the ECT treatments or the medications ... He was like a child ... I mean even when it came to his health care, even when it came down to decide to do the ECT treatments, he basically left it up to me ... he would be tired all the time and he wanted to sleep. He just couldn't make a decision on what to do ... he would follow me around the house everywhere I went because he was so worried about his job ... what was he going to tell them at his work ... he would follow me from room to room to room ... I looked at him and I said, "You are going to have to give me 10 minutes," ... then he would realize what he was doing and he would back off for a little bit ... He just expected me to tell him what to do all the time. He would just get so anxious.

\section{Last Resort}

The anguish of having a mental illness and the patients' poor response to current treatment left many of the patients and family members feeling powerless. Despite their fears of having ECT, many participants began to believe that ECT was their last resort, as noted in the following statements:

We tried all the medications and had gone through and tried to combine medication and nothing was working ... we were at a desperate stage ... ECT. . we had no other choice. (Carol)

She was in and out of mental institutions, when she got real, real, bad and we kept seeking help, seeking different remedies, seeking different medications. Nothing was working so they said ECT needed to be done. (Doris)

\section{Blind Trust}

Many of the participants believed that their final decision to have ECT was predicated on their need to do just what their doctor advised. The following excerpt depicts this theme:

\begin{abstract}
I just believed everything he said ... I agreed with everything he said, believed everything he said ... never challenged anything he said ... I lived with the obligation that I needed to do what he said all the time. (Carol)
\end{abstract}

\section{The Aftermath of Having ECT}

Although some patients and family members felt that ECT diminished their depression and suicidal thoughts, most of the participants emphasized the physical and emotional struggles they experienced following ECT. The aftermath of ECT was divided into the following subthemes: (1) benefits, (2) losses, (2) disheartened feelings, and (3) being poorly informed.

\section{Benefits}

Many of the participants spoke about how they felt ECT helped reduce their depression or suicidal thoughts, as shown in the following excerpt:

\footnotetext{
After the third treatment I woke up in the recovery room and ... it was like a light bulb went on, I felt something different ... It was like things started connecting ... I started caring a little bit ... I started wanting to do stuff and even making plans for the future ....ECT was a God-send for me. (Mike)
}

\section{Losses}

Participants and family members described many losses the patient incurred, and often they associated these losses with having ECT. The following excerpt describes a father's concern for this daughter who he feels has experienced many functional losses since receiving ECT:

She never had motor control again. She can't control her ankles walking in high heel shoes and ECT, of course, is on the brain and the brain, of course, controls all these things and all of her life she has been able to do these things quite well ... I have seen her go into decline. She was once a vibrant and energetic person, and she lives with us, and I see her every day and so I've seen this decline and I'm concerned ... I just think that this [ECT] has caused some problems with my daughter that she hadn't had before. (James)

Amy reports that ECT made her manic and she describes how her behaviors caused her to lose everything that was important to her:

ECT made me manic ... I decided that I was cute and sexy ... went out drinking, dancing, and laughing and all that kind of stuff and was on this big high ... causing me to lose my family ... lose my marriage ... I don't remember hurting my kids, I don't remember saying the things I said to my children ... people tell me I did this and I did that ... It was a nightmare ... it was a real nightmare ... what happened was a total nightmare and I deal with it every day of my life now ... I suffer and I pay for it every day. I have lost everything I had. I lost my husband, my children. If I did not have ECT, I would not have lost my husband. 
Finally Barb talks about how she believes that ECT has taken away her ability to get a job:

It is hard to try and find employment again because most everything that I learned when I got my graduate degree is gone.

Most of the participants attributed loss of their long-term memory to ECT, describing memory loss that was greater than expected. This loss was mourned by both patients and family members. The following excerpts describe their feelings:

She's got a hole in her memory ... her whole memory loss would be like somebody who suffered a major accident with brain trauma or severe head injury and they have a blank space and like there is nothing there. (Tim)

I had my memory taken away. Some of the memories of my husband trying to kill me was taken away, so I was glad of that ... but other things I had forgot, I wish that I hadn't forgot ... like my mother's death, and I can't remember going to the funeral or anything, and I can't remember my children being born. (Sara)

I've lost about 15 years worth of memory. (Barb)

In addition, most patients described loss of ability to independently attend to their activities of daily living (ADLs) because they did not remember what to do immediately after having ECT. These losses were especially difficult for family members, who were often required to provide aftercare and assistance. One patient described forgetting how to take a shower, and another said she would stand in her house and forget which room she was in. The following excerpts describe these feelings:

They discharged me after eight treatments and then I went in as an outpatient for the last two treatments ... but when I got home ... I couldn't remember what to do ... I didn't know how to take a shower ... I don't know if I just forgot what to do and it was kind of all blurry ... and I couldn't put complete thoughts together ... I just wasn't able to function at all. (Mary)

It was my house, but I couldn't remember where anything came from in the house ... I didn't know what room I was in. (Sara)

She didn't know what she was doing. She couldn't even remember how to unlock the front door to our apartment. (Tim)

\section{Disheartened Feelings}

Many of the participants felt disheartened and dismayed by the outcomes of ECT. The following excerpt clearly depicts these feelings:

I was told that it wasn't going to be that bad ... After the first one, I thought this is going to be bad ... but if I want to get better, then I have to proceed and ... it wasn't going to fix things ... you know, I was still hoping that it was going to fix things. But as they progressed, my hatred of them just got worse and worse. And my depression did not get better. (Carol)

Marie was discouraged to see her mother continue to suffer from depression:

ECT works for only a little while... She still gets so depressed.
The small difference ECT made in the life of Carol made her doubt if she had made the right decision to have ECT:

I truthfully don't know if ECT did any good. I got to a better place, but I continued to have some problems after ... in fact I may have even been in the hospital after that ... It just wasn't a dramatic difference. I couldn't say at the end of that that, "Oh, wow, I'm really glad I did that."

\section{Being Poorly Informed}

Although participants never expressed a clear feeling of deceit, they did feel that they had not been completely informed of the risks of ECT.

They [doctors] tell their patients that they will have minor short term memory loss, but that is not necessarily true ... they have caused so much [of my] memory to be gone. (Barb)

So they didn't really tell me a lot and when I expressed concern about the memory loss or anything associated with it, told me that it was an old wives' tale kind of thing ... it hasn't been confirmed in the literature ... it's not really something to worry about ... he didn't feel there was any documentation to cause me concern so I decided to have it ... In reality, there is a memory loss and I hate that I've lost it ... I don't know if they are just hiding things or they think that you are too stupid to know ... or need to know. (Mary)

Family members also expressed anguish about feeling they were not totally informed. Marie describes her feelings about her mother's ECT treatment:

It was the ECT. It was just night and day ... the difference ... night and day. I know I had been used to her being depressed but she still had a fight in her. She was depressed, but when the ECT treatment was done ... she became different and I didn't know this woman ... I was told there would be a little bit of memory loss, but that it would come back ... all the depression will be gone. I would like to of known what could have happened ... like a total personality change. I just wish that it never happened.

Although some patients and family members described positive benefits of ECT, all 16 participants described memory loss that was more than expected. In addition, the patients continued to receive pharmacological interventions and many continued to experience depressive symptoms or feel they were depressed. Yet despite the fact that they felt the loss of memory negatively impacted their quality of life and they were poorly informed of the risks of ECT, some felt that the decision to have ECT was the right one for them. Others were angry at agreeing to have ECT. Both groups said that they would have preferred more information about the possible loss of memory.

\section{DISCUSSION}

The perceptions of patients and their family members about ECT are crucial to understanding the meaning attached to having ECT and the impact it has on quality of life. These perceptions are also important to guide the development of interventions to improve quality of care. This phenomenological study elicited a common theme of struggle, both before and following ECT. 
Before ECT, patients and their families struggled with the symptoms of mental illness including depression, loss of productivity at home and at work, increased relationship discord, and suicidal and parasuicidal behaviors. Both patients and family members described the difficulties of having a serious mental illness and hearing their physician inform them that ECT was the last thing they had to offer.

Many patients and family members described thinking "this has to work" and having high hopes that they would no longer be mentally ill. Additionally, there was much discussion of the appropriateness of ECT and the benefits it might offer. Family members also reported frustration, said that at times they felt they were not part of the decision-making process, even though they would have to provide aftercare. Many of these struggles were accompanied by a "blind trust" patients put in their physicians. Patients and family members described assuming that whatever was recommended was the best option.

Patients and family members described watching videos about ECT, talking with treatment providers and assuming that the information provided was absolute and the risks presented were accurate. Nevertheless, as in the study reviewed by Rose, Wykes, Bindman, and Fleischmann (2005) and the study done by Rajkumar, Saravanan, and Jacob (2007), some of the patients in this study felt they were coerced into giving consent for ECT. In a study by Amazon, McNeedly, Lehr, and Marquardt (2008), patients said they felt they were too depressed to participate in the decision making process. Perhaps when the results were not what patients and family members had hoped for, they remembered the informed consent process as being coercive.

Following ECT, patients and family members experienced additional struggles. Significant losses were described spanning several areas of life and functioning. All patients and family members described memory losses that were greater than anticipated. These losses were especially salient for patients who were not able to remember their children growing up, their educational history, family members' deaths, or special vacations and trips. The type of memory loss these patients described is termed autobiographical memory loss, which can occur after ECT. A number of researchers have found that autobiographical memory problems are more likely to persist than other types of memory problems after ECT. There is some question, however, about whether these memory losses are a result of the depressive illness or ECT (Fraser, O'Carroll, \& Ebmeier, 2008). When the effects of ECT on autobiographical memories were assessed by standardized tests of performance and the subjective experience of patients, conflicting results emerged (Fraser, O'Carroll, \& Ebmeier, 2008). Thus there is a need to take both perspectives into consideration rather than relying on one or the other. Autobiographical memory deficit is clinically the bigger concern for patients and in this study it was the most alarming effect of ECT.

Disheartened feelings emerged when people felt that their lives were made worse or "ruined" by ECT. For these people, it is easy to see how the stress of having a serious mental illness, combined with significant losses, produced more feelings of depression and worthlessness. Many patients and family members felt disappointed and let down by ECT, because they had thought the ECT would reduce depression and/or the need for psychotropic medications. When these results were not achieved and the side effects were greater than anticipated, people felt poorly informed about the risks and benefits of ECT. Many participants felt they were not given enough information about the possibility of losing cherished memories. While participants described watching videos, getting consultation from health care providers, and signing consent forms, they felt the educational materials and consultation did not accurately reflect the side effects they experienced. Specifically, many patients said they were told, "You may experience some short term memory loss," but they actually experienced significant memory loss and a decrease in executive functioning. These patients felt the information they had been given was incomplete. One patient reported that she became "severely manic" following the ECT and said she was never informed that mania was a potential side effect. Many also felt poorly informed about having to remain on medications following ECT. Although there is much evidence that ECT improves depression and reduces symptom severity, many of the participants in this study felt that their quality of life was significantly reduced as a result of ECT.

One of the most important themes in this study was a need for patients and families to be better informed about the risks of ECT. A need for clearer information also was found in a study by Vamos (2008). Fully understanding the risks is essential when giving informed consent. The patient has both a legal and ethical right to be involved in decisions about his or her body. Informed consent must include informing the patient of the relevant risks, benefits, and uncertainties related to all alternative treatments and assessing patients' understanding of these risks. As noted earlier, participants in this study spoke clearly of the need for more information about the risks of ECT.

It is well known that ECT has helped many patients. For unknown reasons, many of the patients who volunteered for this study had a mostly negative experience with ECT and emphasized the negative outcomes. Participants were eager to tell their stories and through volunteering to be a part of the study, they were hoping their voices would be heard. Although their stories may not give a complete picture of the positive and negative consequences of ECT, it is important to not fall into the trap of wanting patients to be grateful for the benefits of ECT and not listening to their complaints. Improving patient care, providing better patient and family education, and giving patients the knowledge to make an informed decision, requires listening to the voices of those who have had not only positive experiences but also negative experiences with ECT. The participants' stories suggest that families should be included in the education about ECT since they are vital in providing the required aftercare. Education must include the benefits as well as the risks and possible long term consequences of ECT. Their stories further emphasize the immediate care needed for a confused 
patient following ECT, and the need to provide both written and verbal instructions to both patient and family member. To ensure adequate informed consent, health care professionals must be cognizant of a patient's understanding of the information provided. Even when all information is presented, a patient's understanding can be less than adequate for informed consent (Jefford \& Moore, 2008); and therefore the patient's competency must be evaluated. This aspect of informed consent can be difficult in mental health, since the mental illness itself may render patients incompetent to consent to treatment for the very condition which prompted them to seek care (Hilton, 2007). One patient in this study clearly said she felt that she was too depressed to give informed consent concerning ECT for herself. She added, "I actually signed the consent, but I didn't have a clue." One might want to consider audiotaping the informed consent process. Psychiatric patients often feel powerless and vulnerable and later may feel coerced if it is not made clear to them that they are expected to actively participate in the decision making process, not blindly comply with their doctor's suggestions. The significance of this study is that the participants stressed the importance of being properly informed of the risk-benefit ratio of ECT. It is everyone's ethical responsibility to assure that the patient and family are properly informed to ensure an informed decision can be made.

Declaration of interest: The authors report no conflicts of interest. The authors alone are responsible for the content and writing of the paper.

\section{REFERENCES}

Amazon, J., McNeely, E., Lehr, S., \& Marquardt, M. (2008). The decision making process of older adults who elect to receive ECT. Journal of Psychosocial Nursing, 46(5), 45-52.

Ding, Z., \& White, P. (2002). Anesthesia for electroconvulsive therapy. Anesthesia Analog, 94, 1351-1364.

Dowman, J., Patel, A., \& Rajput, K. (2005). Electroconvulsive therapy attitudes and misconceptions. The Journal of ECT, 21(2), 84-87.

Fink, M. (2001). ECT has much to offer our patients it should not be ignored. The World Journal of Biological psychiatry, 2(1), 1-8.

Fraser, L., O'Carroll, R., \& Ebmeier, K. (2008). The effect of electroconvulsive therapy on autobiographical memory: A systematic review. Journal of ECT, 24(1), 10-17.
Greenberg, R., \& Kellner, C. (2005). Electroconvulsive therapy a selected review. American Journal of Geriatric Psychiatry, 13(4), 268281.

Hilton, C. (2007). Changes between the 1959 and 1983 Mental Health Acts (England \& Wales), with particular reference to consent to treatment for electroconvulsive therapy. Historical Psychiatry, 18, 217-229.

Jefford, M., \& Moore, R. (2008). Improvement of informed consent and the quality of consent documents. Lancet Onocology, 9(5), 485493.

Khalid, N., Atkins, M., Tredget, J., Giles, M., Champney-Smith, \& Kirov. (2008). The effectiveness of electroconvulsive therapy in treatment resistant depression: A naturalistic study. Journal of ECT, 24(2), 141-145.

Koopowitz, L., Chur-Hansen, A., Reid, S., \& Blashki, M. (2003). The subjective experience of patients who received electroconvulsive therapy. Australian and New Zealand Journal of Psychiatry, 37(1), 49-54.

Lauber, C., Nordt, C., Falcato, L., \& Rossler, W. (2005). Can a seizure help? The public's attitude toward electroconvulsive therapy. Psychiatry Research, 134(2) 205-209.

Lescoe, F.J. (1974). Existentialism. New York: Alba House.

Merleau-Ponty, M. (1962). Phenomenology of perception. New York: Humanities Press

National Institutes of Health National survey sharpens picture of major depression among adults. (2005). http://www.sciencedaily.com/releases/ 2005/10/051004084117.htm. Retrieved on August 20, 2008.

Nuttall, G., Bowersox, M., Douglass, S., McDonald, J., \& Rasmussen, L. (2004). The Journal of ECT, 20(4), 237-241.

Rajkumar, A., Saravanan, B., \& Jacob, K. (2007). Voices of people who have received ECT. Indian Journal of Medical Ethics, 4(4), 157-164.

Reid, W. (1999). Electroconvulsive therapy in psychiatrists and their families. The Journal of ECT, 15(3), 207-212.

Rose, D., Fleischmann, P., Wykes, T., Leese, M., \& Bindman, L. (2003). Patients' perspectives on electroconvulsive therapy: Systematic review. British Journal of Psychiatry, 326(7403), 1363.

Rose, D., Wykes, T., Bindman, L., \& Fleischmann (2005). Information, consent and perceived coercion: Patients' perspectives on electroconvulsive therapy. British Journal of Psychiatry, 186, 54-59.

Scarano, V., Felthous, A., \& Early, T. (2000). The state of electroconvulsive therapy in Texas. Part I: Reported data on 41,660 ECT treatments in 5971 patients. Journal of Forensic Science, 45(6), 1197-1202.

Tharyan, P., \& Adams, C. (2005). Electroconvulsive therapy for schizophrenia. Cochrane Database Systematic Reviews. Issue 2. Art. No.: CD000076.DOI:1002/14651858.CD000076.pub2

Thomas, S. P., \& Pollio, H. R. (2002). Listening to patients. A phenomenological approach to nursing research and practice. New York: Springer.

Vamos, M. (2008). The cognitive side effects of modern ECT: Patient experience or objective measurement? Journal of ECT, 24(1), 18-24.

World Health Organization. http://www.who.int/mental_health/management/ depression/definition/en/. Retrieved on July 15, 2008. 
Copyright of Issues in Mental Health Nursing is the property of Taylor \& Francis Ltd and its content may not be copied or emailed to multiple sites or posted to a listserv without the copyright holder's express written permission. However, users may print, download, or email articles for individual use. 